\title{
MiR-223 levels predicting perioperative bleeding in off-pump coronary artery bypass grafting
}

\author{
Zi Wang ${ }^{1}$, Limin Xia ${ }^{2}$, Qing Xu ${ }^{1}$, Qiuyi Ji ${ }^{1}$, Zhifeng Yao ${ }^{3}$, Qianzhou Lv ${ }^{1}$ \\ ${ }^{1}$ Department of Clinical Pharmacy, ${ }^{2}$ Department of Cardiovascular Surgery, ${ }^{3}$ Department of Cardiology, Zhongshan Hospital, Fudan University, \\ Shanghai, China \\ Contributions: (I) Conception and design: Z Wang, Q Lv, Z Yao; (II) Administrative support: Q Lv, Z Yao; (III) Provision of study materials or \\ patients: Q Lv, Zhifeng Yao; (IV) Collection and assembly of data: Z Wang, L Xia, Q Ji; (V) Data analysis and interpretation: Z Wang, Q Xu; (VI) \\ Manuscript writing: All authors; (VII) Final approval of manuscript: All authors. \\ Correspondence to: Prof. Qianzhou Lv, MS. Department of Clinical Pharmacy, Zhongshan Hospital, Fudan University, 180 Feng Lin Road, Shanghai \\ 200032, China. Email: 13916088938@163.com; Dr. Zhifeng Yao, MD. Department of Cardiology, Zhongshan Hospital, Fudan University, 180 Feng \\ Lin Road, Shanghai 200032, China. Email: Yao.zhifeng@zs-hospital.sh.cn.
}

Background: To investigate the predictive value of platelet-related microRNAs (miRNAs) for bleeding during and after off-pump coronary artery bypass grafting (OPCABG) and the influence of dual antiplatelet therapy (DAPT) on miRNAs.

Methods: This prospective study included 59 patients scheduled for OPCABG. The plasma miR-126 and miR-223 levels were measured and platelet aggregation was determined by thromboelastography during DAPT. The plasma miRNA levels were compared between patients treated with ticagrelor or clopidogrel. Multivariable logistic regression analysis was performed to determine the independent risk factors for bleeding during and after surgery. Active bleeding was defined as a blood loss $>1.5 \mathrm{~mL} / \mathrm{kg} / \mathrm{h}$ for 6 consecutive hours within the first 24 hours or in case of reoperation during the first 12 postoperative hours. Severe perioperative bleeding was defined using the universal definition of perioperative bleeding in adult cardiac surgery.

Results: Higher circulating miR-223 levels [odds ratio $(\mathrm{OR})=1.348,95 \%$ confidence interval (CI): $1.001-$ 1.814, $\mathrm{P}=0.047$ ] and lower body mass index (OR $=0.648,95 \% \mathrm{CI}: 0.428-0.980, \mathrm{P}=0.040)$ were independent predictors for severe perioperative bleeding in OPCABG. Ticagrelor treatment led to significant increases in circulating miR-223 levels compared with clopidogrel treatment.

Conclusions: The plasma miR-223 levels served as a predictor for bleeding during and after OPCABG. Circulating miR-223 levels were significantly elevated with ticagrelor treatment compared with clopidogrel treatment. MiR-223 may be a novel biomarker for bleeding in cardiac surgery and can help explain the different efficacies of ticagrelor and clopidogrel.

Keywords: Off-pump coronary artery bypass grafting (OPCABG); miRNA; ticagrelor; clopidogrel; bleeding

Submitted Feb 28, 2020. Accepted for publication Sep 25, 2020.

doi: $10.21037 / \mathrm{atm}-20-2022 \mathrm{~b}$

View this article at: http://dx.doi.org/10.21037/atm-20-2022b

\section{Introduction}

Coronary artery bypass grafting (CABG) surgery is an effective treatment for patients with 3-vessel coronary artery disease (CAD). Dual antiplatelet therapy (DAPT) prior to CABG may increase the risks of postoperative hemorrhage and blood product transfusion, leading to enhanced in-hospital mortality and morbidity rates $(1,2)$. Off-pump coronary artery bypass grafting (OPCABG) is an alternative surgical technique that has been shown to reduce postoperative bleeding risk with recent clopidogrel exposure, which may be attributed to preserved coagulation and platelet function (3). Some indicators, including the 


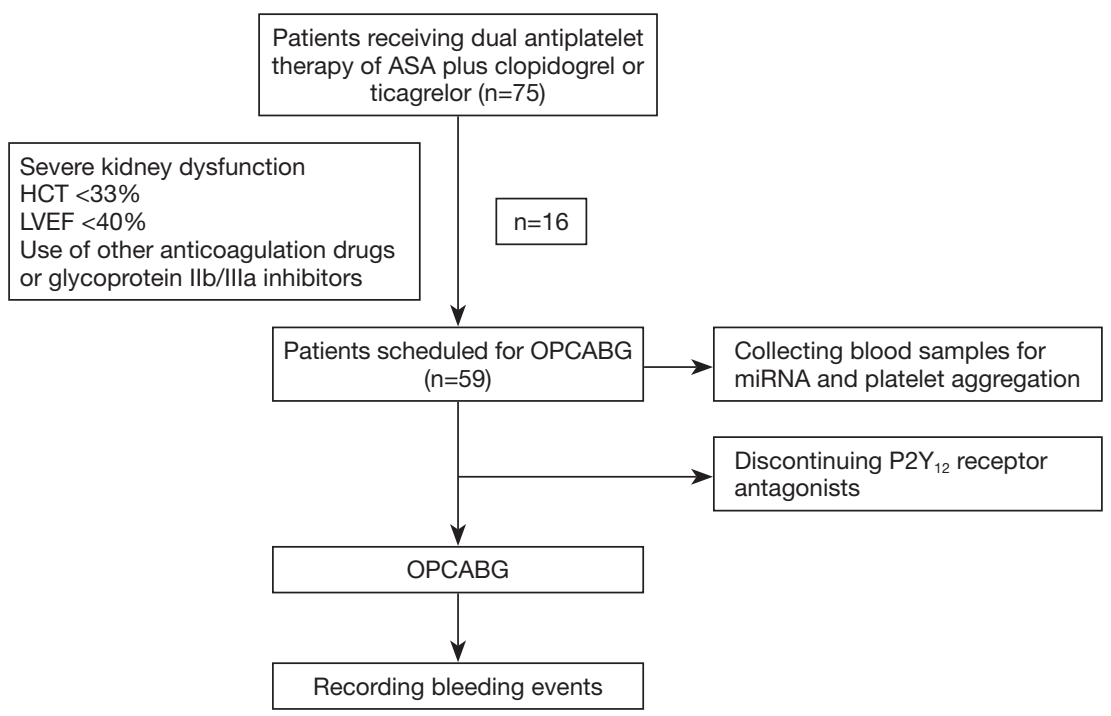

Figure 1 Flow chart. ASA, aspirin; HCT, hematocrit; LVEF, left ventricular ejection fraction; OPCABG, off-pump coronary artery bypass grafting.

preoperative fibrinogen concentration (4), body mass index (BMI) (5), platelet function (6) and preoperative C-reactive protein levels (7), were reported to be associated with hemorrhage and blood product transfusion requirements during and after CABG. Indicators that can accurately predict perioperative bleeding and transfusion may help surgeons to conduct better prognosis evaluations and thus make safer decisions for cardiac surgery patients. MicroRNAs (miRNAs) are small noncoding RNAs that can regulate gene expression. MiRNAs bind to 3 '-untranslated regions (UTR) of target messenger RNAs, thus directing posttranscriptional repression (8). MiR223, the most richly expressed miRNA in platelets and megakaryocytes, plays a role in the development of the hematopoietic lineage (9). Another miRNA, miR-126, is highly enriched in endothelial cells as well as in platelets, and is responsible for maintaining endothelial homeostasis and vascular integrity (10). Recent research has shown that miR-126 and miR-223 levels are correlated with platelet function tests in acute coronary syndrome patients and might be employed to assess the responsiveness to antiplatelet agents (11-13). Additionally, these miRNAs in circulation were found to predict cardiovascular events in CAD patients $(14,15)$. However, there is no study to date that has investigated the associations among miRNAs and clinical outcomes in cardiac surgery patients. This study aimed to investigate the relationships between plateletrelated miRNAs and perioperative bleeding in OPCABG surgery patients and the impact of DAPT on plateletrelated miRNAs.

We present the following article in accordance with the STROBE reporting checklist (available at http://dx.doi. org/10.21037/atm-20-2022b).

\section{Methods}

\section{Patients}

The study protocol conformed to the ethical guidelines of the Declaration of Helsinki (as revised in 2013) and was approved by the Ethics Committee of Zhongshan Hospital, Fudan University (No. B2017-102). A signed informed consent form was obtained from each of the study subjects or their legal guardians. CAD patients who received DAPT of aspirin (ASA) plus clopidogrel or ticagrelor and were scheduled for OPCABG were included in the study. Patients meeting any of the following criteria were excluded from the study: (I) history of cardiac surgery; (II) severe liver or kidney insufficiency; (III) severe infectious diseases; (IV) malignant diseases; (V) left ventricular ejection fraction $<40 \%$; (VI) hematocrit (HCT) <33\%; (VII) platelet count $<100,000 \mathrm{~mm}^{3}$; (VIII) abnormal range of prothrombin time or activated partial thromboplastin time; or (IX) use of glycoprotein IIb/IIIa inhibitors or anticoagulation drugs at admission (Figure 1).

A total of $59 \mathrm{CAD}$ patients scheduled for OPCABG from 
January 2018 to December 2018 were enrolled in this study. As part of our center's routine practices, ASA treatment remained in place and $\mathrm{P} 2 \mathrm{Y}_{12}$ receptor antagonist treatment was halted in the patients at least 5 days prior to OPCABG. Patients resumed $\mathrm{P} 2 \mathrm{Y}_{12}$ receptor antagonist treatment on the first day after surgery.

All surgical procedures were conducted by a single surgeon through a median sternotomy. Systemic heparinization $(1 \mathrm{mg} / \mathrm{kg})$ was used along with additional doses to maintain an activated clotting time $>300 \mathrm{~s}$. After surgery, protamine sulfate (1:1) was used to neutralize heparin activity. A cell salvage device was used during the operation and salvaged blood was reinfused into the patient before the completion of the operation. All patients were transferred to the intensive care unit after surgery. Allogenic packed red blood cells (pRBCs) were transfused when the hemoglobin $(\mathrm{Hb})$ level was $<7 \mathrm{~g} / \mathrm{L}$. Fresh frozen plasma (FFP) was transfused when the blood loss exceeded $200 \mathrm{~mL}$ per hour for 2 consecutive hours after surgery and the postoperative international normalized ratio was greater than 1.5. Platelets were transfused when the postoperative platelet count was $<50,000 / \mathrm{mm}^{3}$ and the blood loss exceeded $200 \mathrm{~mL}$ per hour for 2 consecutive hours after surgery. Surgical re-exploration was considered when the chest tube drainage (CTD) volume was $>200 \mathrm{~mL} / \mathrm{h}$ for 6 consecutive hours or $>400 \mathrm{~mL}$ during the first hour. Bleeding assessments were based on active bleeding described in previous research (16) and the universal definition of perioperative bleeding (UDPB) in adult cardiac surgery (17). Active bleeding was defined as a blood loss $>1.5 \mathrm{~mL} / \mathrm{kg} / \mathrm{h}$ for 6 consecutive hours within the first 24 hours or reoperation for bleeding during the first 12 hours after surgery (16). Severe bleeding occurred when one or more of the six following criteria were met: CTD volume $>1,000 \mathrm{~mL}$ within the first 12 hours after surgery; delayed sternal closure; surgical re-exploration because of bleeding; use of recombinant factor VIIa; transfusion of $\geq 5$ units of RBCs within 24 hours of chest closure; and transfusion of $\geq 5$ units of plasma within 24 hours of chest closure $(16,18)$.

\section{Detection of the percentage of platelet aggregation}

The percentage of platelet aggregation was assessed by Thromboelastograph ${ }^{\circledR}$ Hemostasis Analyzer with a platelet mapping assay (Hemoscope Corp, Niles, IL, USA). The contribution of the $\mathrm{P} 2 \mathrm{Y}_{12}$ receptor or cyclooxygenase pathways to the clot formation were measured by adding the agonist adenosine diphosphate (ADP) or arachidonic acid (AA) (19).

\section{$R N A$ isolation and real-time quantitative polymerase chain reaction}

The first $2-3 \mathrm{~mL}$ of blood was discarded to avoid platelet activation and then peripheral venous blood samples $(6 \mathrm{~mL})$ were collected for miRNA detection in plastic tubes containing ethylenediaminetetraacetic acid anticoagulant (20). The blood was immediately processed to avoid the swelling of platelets and plasma was extracted using a 2 -step centrifugation protocol within 2 hours $(20,21)$. Samples were first centrifuged at 3,000 rpm for 10 minutes at $4{ }^{\circ} \mathrm{C}$, and then the collected supernatants were centrifuged at $10,000 \mathrm{rpm}$ for 10 minutes at $4{ }^{\circ} \mathrm{C}$. The final supernatants were carefully transferred to RNase-free tubes and stored at $-80^{\circ} \mathrm{C}$ for the subsequent laboratory analyses.

The total RNA was extracted from the collected plasma samples using a miRNeasy Plasma Kit (Qiagen, Hilden, Germany) according to the manufacturer's instructions. The production of RNA was detected by a NanoDrop 2000 spectrophotometer (Thermo Scientific, USA). Heparin use was halted in all patients before the blood for total RNA extraction was collected because several studies suggested that heparin can interfere with the quantification of miRNA (22). RNA was reversely transcribed to singlestrand complementary DNA using miScript Reverse Transcriptase Mix (Qiagen, Hilden, Germany). The realtime polymerase chain reaction was carried out using a LightCycler 480 II Real-time PCR Instrument (Roche, Switzerland) with QuantiFast SYBR Green PCR Master Mix (Qiagen, Hilden, Germany). Melting curve analysis was performed to assess the specificity of the expected PCR products. The threshold cycle $(\mathrm{Ct})$ was defined as the cycle number at which the fluorescence exceeded the preset threshold value. Ct values greater than 40 were treated as 40. The expression levels of miRNAs were normalized to cel-miR-39 and calculated using the $2^{-\Delta \Delta C t}$ method (23).

\section{Statistical analysis}

Statistical analysis was performed using SPSS version 21.0 (IBM Corporation, Armonk, NY, USA). The normality of the distribution of continuous variable was assessed using the Shapiro-Wilk normality test. All continuous variables were presented as the mean \pm standard deviation 
Table 1 Patient characteristics

\begin{tabular}{lc}
\hline Characteristics & Patients $(\mathrm{n}=59)$ \\
\hline Age, median $\pm \mathrm{SD}$, years & $64.46 \pm 9.45$ \\
Male, $\mathrm{n}(\%)$ & $46(77.97)$ \\
BMI, mean $\pm \mathrm{SD}, \mathrm{kg} / \mathrm{m}^{2}$ & $23.55 \pm 2.88$ \\
Active bleeding, $\mathrm{n}(\%)$ & $3(5.08)$ \\
UDPB events, $\mathrm{n}(\%)$ & \\
Class 3 or class 4 UDPB bleeding & $8(13.56)$ \\
$\begin{array}{l}\text { Chest tube drainage volume }>1,000 \text { mL } \\
\text { within } 12 \text { hours of chest closure }\end{array}$ & $2(3.39)$ \\
$\begin{array}{l}\text { Delayed sternal closure } \\
\text { Surgical re-exploration because of bleeding }\end{array}$ & $2(3.39)$ \\
$\begin{array}{l}\text { Use of recombinant factor Vlla } \\
\text { Transfusion of } \geq 5 \text { units of RBCs within } \\
24 \text { hours of chest closure }\end{array}$ & $6(10.17)$ \\
$\begin{array}{l}\text { Transfusion of } \geq 5 \text { units of plasma within } \\
24 \text { hours of chest closure }\end{array}$ & $5(8.47)$ \\
\hline
\end{tabular}

BMI, body mass index; UDPB, universal definition of perioperative bleeding; RBCs, red blood cells.

if normally distributed, otherwise as the median and interquartile range (IQR), and were tested using the Student's $t$-test or the Mann-Whitney $U$ test. A $\log _{2}$ transformation was applied to the miRNA data. All categorical variables were expressed as frequencies and percentages, and were tested using the chi-squared test, or Fisher's exact test if necessary. Multivariable logistic regression analysis was used to determine the independent contribution of platelet-related miRNAs to perioperative hemorrhage. First, variables including age, gender, BMI, smoking status, diabetes mellitus, use of $\mathrm{P} 2 \mathrm{Y}_{12}$ receptor antagonists (clopidogrel or ticagrelor), AA-induced platelet aggregation, ADP-induced platelet aggregation, $\mathrm{Hb}, \mathrm{HCT}$, platelet counts, mean platelet volume (MPV), plateletcrit (PCT), platelet distribution width (PDW), and miRNA levels were included in the model with univariable analysis for relationship with active bleeding and severe perioperative bleeding. The variables that yielded a $\mathrm{P}$ value of $<0.2$ in the univariable analysis were entered into the multivariable logistic regression analysis. The results were expressed as odds ratios (ORs) along with the 95\% confidence intervals (CIs). Statistical significance was assumed with two-sided $\mathrm{P}$ values of $<0.05$.

\section{Results}

\section{Patient characteristics}

This study enrolled 59 CAD patients scheduled for OPCABG. The mean age of these patients was $64.46 \pm 9.45$ years, and among them, $77.97 \%$ were men. Three patients $(5.08 \%)$ experienced active bleeding and eight patients experienced severe perioperative bleeding $(13.56 \%)$ (Table 1).

\section{MiRNAs and bleeding}

The model using univariable analysis indicated that BMI and plasma miR-223 levels yielded $\mathrm{P}<0.2$ for a relationship with active bleeding. These two variables together with age and gender were tested in the multivariable logistic regression analysis. However, none of these selected variables independently predicted active bleeding (Table 2). Another model built with plasma miR-126 also showed no relationship between miR-126 levels and active bleeding (Table S1).

The model using univariable analysis indicated that the $\mathrm{P}$ values of BMI, ADP-induced platelet aggregation and miR-223 levels were $<0.20$ for a relationship with severe perioperative bleeding. These three variables together with age and gender were included in the multivariable logistic regression analysis. A lower $\mathrm{BMI}(\mathrm{OR}=0.648$, 95\% CI: 0.428-0.980, $\mathrm{P}=0.040)$ and higher level of miR$223(\mathrm{OR}=1.348,95 \% \mathrm{CI}: 1.001-1.814, \mathrm{P}=0.047)$ were independent predictors of severe perioperative bleeding (Table 3). Another model built with plasma miR-126 levels showed that there was no relationship between the miR-126 levels and severe perioperative bleeding (Table S2).

\section{$P 2 Y_{12}$ receptor antagonists and miRNAs}

There was no difference in the baseline data at admission between patients taking clopidogrel or ticagrelor (Table 4). ADP-induced platelet aggregation was significantly higher in patients treated with clopidogrel compared with ticagrelor [39.20\% (IQR, 23.43-65.65\%) versus $17.50 \%$ (IQR, 8.90-28.70\%), $\mathrm{P}=0.002]$. There was no difference in AA-induced platelet aggregation between the two groups. The relative expression of miR-223, but not miR-126, was significantly higher in the ticagrelor group than in the clopidogrel group [6.04 (IQR, 2.93-8.68) versus 3.94 (IQR, 2.64-5.13), $\mathrm{P}=0.046]$ (Table 5). 
Table 2 Risk factors for active bleeding

\begin{tabular}{|c|c|c|c|c|}
\hline \multirow{2}{*}{ Factors } & \multicolumn{2}{|c|}{ Univariable analysis } & \multicolumn{2}{|c|}{ Multivariable analysis } \\
\hline & OR $(95 \% \mathrm{Cl})$ & $P$ value & OR $(95 \% \mathrm{Cl})$ & $P$ value \\
\hline Age $>65$ years & $1.733(0.148-20.323)$ & 0.661 & $1.192(0.033-43.518)$ & 0.924 \\
\hline Male & $0.605(0.051-7.215)$ & 0.691 & $0.435(0.008-23.574)$ & 0.683 \\
\hline Smoking & $0.620(0.053-7.240)$ & 0.703 & - & - \\
\hline Diabetes & $0.667(0.057-7.788)$ & 0.746 & - & - \\
\hline AA-induced platelet aggregation & $0.991(0.930-1.057)$ & 0.792 & - & - \\
\hline ADP-induced platelet aggregation & $0.981(0.926-1.038)$ & 0.501 & - & - \\
\hline Use of ticagrelor & $1.103(0.655-1.827)$ & 0.705 & - & - \\
\hline $\mathrm{Hb}$ & $1.027(0.956-1.104)$ & 0.463 & - & - \\
\hline MPV & $1.305(0.502-3.391)$ & 0.584 & - & - \\
\hline PCT & $0.372(0.000-442.129)$ & 0.923 & - & - \\
\hline PDW & $1.139(0.779-1.665)$ & 0.503 & - & - \\
\hline Plasma miR-223 & $1.393(0.979-1.982)$ & 0.066 & $1.864(0.979-3.551)$ & 0.058 \\
\hline
\end{tabular}

$\mathrm{Log}_{2}$ transformation was applied to miRNA data. BMI, body mass index; AA, arachidonic acid; ADP, adenosine diphosphate; Hb, hemoglobin; Hct, hematocrit; PLT, platelet; MPV, mean platelet volume; PCT, plateletcrit; PDW, platelet distribution width.

Table 3 Risk factors for severe perioperative bleeding

\begin{tabular}{|c|c|c|c|c|}
\hline Factors & \multicolumn{2}{|c|}{ Univariable analysis } & \multicolumn{2}{|c|}{ Multivariable analysis } \\
\hline Age $>65$ years & $2.885(0.531-15.662)$ & 0.220 & $1.346(0.1666-10.878)$ & 0.781 \\
\hline Male & $0.923(0.164-5.187)$ & 0.928 & $2.857(0.226-36.178)$ & 0.148 \\
\hline Smoking & $2.381(0.512-11.063)$ & 0.268 & - & - \\
\hline AA-induced platelet aggregation & $0.974(0.921-1.030)$ & 0.357 & - & - \\
\hline ADP-induced platelet aggregation & $0.965(0.924-1.007)$ & 0.102 & $0.956(0.905-1.011)$ & 0.115 \\
\hline Use of ticagrelor & $0.983(0.589-1.643)$ & 0.949 & - & - \\
\hline MPV & $1.000(0.513-1.949)$ & 0.999 & - & - \\
\hline РCT & $12.671(0.000-373.696)$ & 0.689 & - & - \\
\hline PDW & $0.984(0.732-1.324)$ & 0.916 & - & - \\
\hline Plasma miR-223 & $1.201(0.972-1.485)$ & 0.090 & $1.348(1.001-1.814)$ & 0.047 \\
\hline
\end{tabular}

$\mathrm{Log}_{2}$ transformation was applied to miRNA data. BMI, body mass index; AA, arachidonic acid; ADP, adenosine diphosphate; Hb, hemoglobin; Hct, hematocrit; PLT, platelet; MPV, mean platelet volume; PCT, plateletcrit; PDW, platelet distribution width. 


\section{Page 6 of 10}

Table 4 Patient characteristics in clopidogrel group and ticagrelor group

\begin{tabular}{|c|c|c|c|}
\hline Characteristics & $\begin{array}{l}\text { Clopidogrel } \\
\quad(n=32)\end{array}$ & $\begin{array}{l}\text { Ticagrelor } \\
(n=27)\end{array}$ & $P$ value \\
\hline Age, mean $\pm S D$, years & $66.22 \pm 8.13$ & $62.37 \pm 10.59$ & 0.120 \\
\hline Male, n (\%) & $25(78.1)$ & $21(77.8)$ & 0.974 \\
\hline $\mathrm{BMI}$, mean $\pm \mathrm{SD}, \mathrm{kg} / \mathrm{m}^{2}$ & $23.71 \pm 2.55$ & $23.37 \pm 3.27$ & 0.661 \\
\hline Smoke, n (\%) & $14(43.8)$ & $12(44.4)$ & 1.000 \\
\hline Hypertension, n (\%) & $27(84.4)$ & $19(70.4)$ & 0.224 \\
\hline Diabetes mellitus, n (\%) & $15(46.9)$ & $10(37.0)$ & 0.598 \\
\hline \multicolumn{4}{|c|}{ Medication on admission, $\mathrm{n}(\%)$} \\
\hline Statins & $32(100.0)$ & $27(100.0)$ & 1.000 \\
\hline ACEI/ARB & $13(68.4)$ & $6(31.6)$ & 0.168 \\
\hline $\begin{array}{l}\text { Calcium-channel } \\
\text { blockers }\end{array}$ & $15(53.6)$ & $13(46.4)$ & 1.000 \\
\hline \multicolumn{4}{|c|}{ Laboratory data, mean \pm SD } \\
\hline $\mathrm{Hb}, \mathrm{g} / \mathrm{L}$ & $127.69 \pm 17.37$ & $132.19 \pm 16.17$ & 0.311 \\
\hline $\mathrm{HCT}, \%$ & $38.76 \pm 4.76$ & $40.16 \pm 4.56$ & 0.255 \\
\hline PLT count, $\times 10^{9} / \mathrm{L}$ & $214.15 \pm 62.10$ & $218.33 \pm 50.89$ & 0.786 \\
\hline PCT, \% & $0.25 \pm 0.07$ & $0.23 \pm 0.05$ & 0.444 \\
\hline MPV, fL & $11.26 \pm 1.21$ & $11.03 \pm 1.00$ & 0.425 \\
\hline PDW, \% & $13.83 \pm 2.89$ & $13.46 \pm 2.15$ & 0.591 \\
\hline RBC count, $\times 10^{12} / \mathrm{L}$ & $4.31 \pm 0.67$ & $4.36 \pm 0.51$ & 0.734 \\
\hline APTT, s & $27.38 \pm 2.62$ & $26.91 \pm 1.73$ & 0.429 \\
\hline PT, s & $11.58 \pm 1.21$ & $11.42 \pm 0.62$ & 0.529 \\
\hline
\end{tabular}

$\mathrm{BMI}$, body mass index; $\mathrm{ACEl}$, angiotensin converting enzyme inhibitor; ARB, angiotensin receptor blocker; $\mathrm{Hb}$, hemoglobin; HCT, hematocrit; PLT, platelet; PCT, plateletcrit; MPV, mean platelet volume; PDW, platelet distribution width; RBC, red blood cell; APTT, activated partial thromboplastin time; PT, prothrombin time.

\section{Discussion}

Previous literature suggested that platelet-related miRNA levels were associated with platelet reactivity (20) and served as predictors for cardiovascular events $(14,24)$. However, few studies have investigated the predictive values of these miRNAs in cardiac surgery patients. This observational study included two specific miRNAs known to be associated with platelet function and investigated their predictive values in OPCABG. We found that plateletrelated miRNA-223 may serve as an independent predictor

\section{Wang et al. MiR-223 levels predicting perioperative bleeding}

Table 5 Platelet aggregation and the relative expression of miRNA levels

\begin{tabular}{lccc}
\hline Variables & Clopidogrel & Ticagrelor & $P$ value \\
\hline AA-induced platelet & 15.05 & 6.50 & 0.105 \\
aggregation, \% & $(4.20-27.58)$ & $(3.40-16.30)$ & \\
ADP-induced platelet & 39.20 & 17.50 & 0.002 \\
aggregation, \% & $(23.43-65.65)$ & $(8.90-28.70)$ & \\
miRNA-126 $\left(-\log _{2}\right)$ & $3.07(0.69-5.11)$ & 3.44 & 0.933 \\
& & $(-0.72$ to 8.10$)$ & \\
miRNA-223 $\left(-\log _{2}\right)$ & 3.94 & 6.04 & 0.046 \\
& $(2.64-5.13)$ & $(2.93-8.68)$ & \\
\hline
\end{tabular}

Data are presented as median (interquartile range); $\log _{2}$ transformation was applied to miRNA data. AA, arachidonic acid; ADP, adenosine diphosphate.

for severe perioperative bleeding, and that treatment with the novel $\mathrm{P} 2 \mathrm{Y}_{12}$ receptor antagonist ticagrelor resulted in elevated circulating miR-223 levels compared with clopidogrel in CAD patients.

We chose to study miR-223 and miR-126 because they were reported to regulate $\mathrm{P} 2 \mathrm{Y}_{12} \mathrm{mRNA}$, thus playing an important role in modulating platelet functions $(25,26)$. A putative binding site for miR-223 has been identified in the 3 '-UTR of the mRNA encoding P2 $\mathrm{Y}_{12}$ which is known to amplify platelet aggregation by agonists, and experimental research has indicated that $\mathrm{P}_{2} \mathrm{Y}_{12}$ expression could be regulated by miR-223 in human platelets (21). It can be hypothesized that modulation of miR-223 levels influences the $\mathrm{P} 2 \mathrm{Y}_{12}$ expression and platelet aggregation which are related to cardiovascular events. Recently, Schulte et al. suggested that high miR-223 levels reliably predicted future cardiovascular deaths in CAD patients (HR: 2.23, $\mathrm{P}=0.011$ ) (14). In contrast, Keller et al. showed that all-cause 5 -year mortality rates tended to be associated with lower miR-223 level (HR: 0.30, $\mathrm{P}=0.063$ ) (27). However, to date, no study has focused on the predictive value of circulating miR-223 levels on clinical outcomes in cardiac surgery patients. Patients treated with DAPT have increased risks of perioperative hemorrhage and transfusion after surgery (28), leading to higher mortality rates and resource utilization $(14,15)$. Previous studies have shown that platelet function may predict blood loss and transfusion requirements after CABG (29). However, different detection methods of platelet function testing may lead to different conclusions. A recent study on 1,069 patients evaluated the capability of multiple platelet function tests, including light transmittance aggregometry, VerifyNow $\mathrm{P} 2 \mathrm{Y}_{12}$ and Plateletworks 
assays, and the IMPACT-R and the platelet function analysis system (PFA-100), to predict clinical outcomes. As a result, researchers found that none of the performed tests were able to differentiate between patients with and without bleeding or predict minor or major bleeding after discharge (30). Due to the limitations in clinical practice, current guidelines do not recommend routine platelet function tests to adjust antiplatelet therapy (31). The discovery of novel biomarkers that can predict perioperative hemorrhage in cardiac surgery would be useful. Postoperative bleeding can be assessed by CTD volume, which is easily measured and has previously been used as an outcome measurement in clinical research (32). However, the CTD volume after surgery may not reflect the severity of bleeding in an accurate or timely manner. In the present study, active bleeding and UDPB were used to evaluate the severity of hemorrhage in cardiac surgery. Active bleeding, adjusted to body weight, has supposedly been to assess realtime bleeding after surgery, and UDPB creates a simple 5 -class system to assess the severity of bleeding, which can be applied in practice and in clinical investigations to classify perioperative bleeding $(16,17)$. In the present study, we did not find any variable that was related to active bleeding. In fact, we found that higher circulating miR-223 levels were independent predictors of severe perioperative bleeding according to the UDPB. This may be because the UDPB consisted not only of excessive blood loss but also of blood product transfusion requirements. Previous studies suggested that severe perioperative bleeding as classified by UDPB was related to a poor prognosis (17). Therefore, our findings indicate that circulating miR-223 levels may be a novel biomarker of bleeding events and clinical outcomes in cardiac surgery patients.

The present study also showed that the more potent $\mathrm{P} 2 \mathrm{Y}_{12}$ inhibitor, ticagrelor significantly decreased the percentage of $\mathrm{ADP}$-induced platelet aggregation and increased circulating miR-223 levels in CAD patients. This was in line with a previous study that showed that plasma miR-223 levels were elevated with decreasing platelet reactivity (20). In addition, a recent study also investigated the influence of $\mathrm{P} 2 \mathrm{Y}_{12}$ inhibitors on the expression of miR126, miR-223, miR-21, and miR-50, and revealed similar results. The same research group also suggested that miR223 levels were not significantly influenced by the cessation of $\mathrm{P} 2 \mathrm{Y}_{12}$ inhibitor therapy for 10 days (21). This may explain the predictive value of miR-223 levels for perioperative bleeding in our study even after discontinuing ticagrelor and clopidogrel prior to surgery for approximately 5 days.
In contrast, Carino et al. reported reduced circulating miR223 and miR-126 levels after switching from clopidogrel to ticagrelor (33). Another study conducted by Willeit et al. also suggested that further platelet inhibition by prasugrel decreased miR-223 and miR-126 levels in symptomatic carotid atherosclerosis patients (13). This discrepancy may be explained by the long-term intake of DAPT in our study's patients, which might cause chronic adaption at the level of RNA transcription, while patients in Carino's and Willeit's studies had a shorter medication duration (29). In contrast to the miR-223 findings, we did not observe any different effects of clopidogrel and ticagrelor on circulating miR-126 levels in our study. This may be because plasma miR-126 was affected by multiple factors such as gene sequence variations (34), ASA treatment (35), smoking status and diabetes mellitus (36). These results suggest miR-223 may be a novel biomarker for assessing responsiveness to antiplatelet therapy. Compared with clopidogrel, ticagrelor was shown to increase local blood flow (37), increase the inhibitory effect on platelet aggregation, attenuate vascular dysfunction and atherogenesis by inhibiting inflammatory activation (38), and increase the sensation of dyspnea (39). Ticagrelor also induced faster, greater, and more consistent $\mathrm{P} 2 \mathrm{Y}_{12}$ inhibition, and significantly reduced the rate of death from vascular causes, myocardial infarction, or stroke, compared with clopidogrel (40). One explanation for these additional effects of ticagrelor may be the increased extracellular adenosine levels that are present. However, the increased adenosine was still not enough to explain the biological pleiotropic effects after ticagrelor treatment (41). MiR-223 has been demonstrated to be involved in many pathological processes, including angiogenesis, vascular remodeling, inflammation, arrhythmia promotions (42), and the reversal of experimental pulmonary arterial hypertension (43), so the different modulatory effects on miR-223 by ticagrelor compared with clopidogrel may help to explain the pleiotropic effects of ticagrelor and the different efficacies of the two drugs.

In conclusion, our study indicated that circulating miR-223 levels served as independent predictors for perioperative bleeding in OPCABG patients. Treatment with the novel $\mathrm{P} 2 \mathrm{Y}_{12}$ receptor antagonist, ticagrelor resulted in elevated circulating miR-223 levels and decreased ADPinduced platelet aggregation compared with clopidogrel treatment. These results suggest that miR-223 may be a novel biomarker for cardiac surgery patients and may help explain the different efficacies of ticagrelor and clopidogrel.

The present study has several limitations. First, the 
sample size was small and this was a single-center study. In addition, we only chose two platelet-related miRNAs in our study; however, recent research has shown that other miRNAs were also associated with cardiovascular events in CAD patients. Furthermore, our study only used thromboelastography to test platelet function. However, different methods for platelet function testing may lead to different results. Therefore, other platelet function tests should also be investigated. Further studies will be needed to explore these miRNAs in detail.

\section{Acknowledgments}

Funding: This work was supported by Zhongshan Hospital affiliated with Fudan University (grant number 2018ZSLC30).

\section{Footnote}

Reporting Checklist: The authors have completed the STROBE reporting checklist. Available at http://dx.doi. org/10.21037/atm-20-2022b

Data sharing statement: Available at http://dx.doi. org/10.21037/atm-20-2022b

Peer Review File: Available at http://dx.doi.org/10.21037/ atm-20-2022b

Conflicts of Interest: All authors have completed the ICMJE uniform disclosure form (available at http://dx.doi. org/10.21037/atm-20-2022b). The authors have no conflicts of interest to declare.

Ethical Statement: The authors are accountable for all aspects of the work in ensuring that questions related to the accuracy or integrity of any part of the work are appropriately investigated and resolved. The study protocol conformed to the ethical guidelines of the Declaration of Helsinki (as revised in 2013) and was approved by the Ethics Committee of Zhongshan Hospital, Fudan University (No. B2017-102). A signed informed consent form was obtained from each of the study subjects or their legal guardians.

Open Access Statement: This is an Open Access article distributed in accordance with the Creative Commons Attribution-NonCommercial-NoDerivs 4.0 International License (CC BY-NC-ND 4.0), which permits the non- commercial replication and distribution of the article with the strict proviso that no changes or edits are made and the original work is properly cited (including links to both the formal publication through the relevant DOI and the license). See: https://creativecommons.org/licenses/by-nc-nd/4.0/.

\section{References}

1. Salehiomran A, Ahmadi H, Karimi A, et al. Transfusion associated in-hospital mortality and morbidity in isolated coronary artery bypass graft surgery. Cent Eur J Med 2009;4:286-92.

2. Murphy GJ, Reeves BC, Rogers CA, et al. Increased mortality, postoperative morbidity, and cost after red blood cell transfusion in patients having cardiac surgery. Circulation 2007;116:2544-52.

3. Frankel TL, Stamou SC, Lowery RC, et al. Risk factors for hemorrhage-related reexploration and blood transfusion after conventional versus coronary revascularization without cardiopulmonary bypass. Eur J Cardiothorac Surg 2005;27:494-500.

4. Karlsson M, Ternström L, Hyllner M, et al. Plasma fibrinogen level, bleeding, and transfusion after on-pump coronary artery bypass grafting surgery: A prospective observational study. Transfusion 2008;48:2152-8.

5. Nolan HR, Davenport D, Ramaiah C. BMI is an independent preoperative predictor of intraoperative transfusion and postoperative chest-tube output. Int J Angiol 2013;22:31-6.

6. Della Corte A, Bancone C, Spadafora A, et al. Postoperative bleeding in coronary artery bypass patients on double antiplatelet therapy: predictive value of preoperative aggregometry. Eur J Cardiothorac Surg 2017;52:901-8.

7. Liu X, Zhang $W$, Chen N, et al. Can preoperative C-reactive protein predict bleeding after on-pump coronary artery bypass grafting? Ann Thorac Surg 2020;109:541-6.

8. Bartel DP. MicroRNAs: Target recognition and regulatory functions. Cell 2009;136:215-33.

9. Fuentes E, Palomo I, Alarcón M. Platelet miRNAs and cardiovascular diseases. Life Sci 2015;133:29-44.

10. Wang S, Aurora AB, Johnson BA. The endothelial-specific microRNA miR-126 governs vascular integrity and angiogenesis. Dev Cell 2008;15:261-71.

11. McManus DD, Freedman JE. MicroRNAs in platelet function and cardiovascular disease. Nat Rev Cardiol 2015;12:711-7. 
12. Kaudewitz D, Skroblin P, Bender LH. Association of microRNAs and yRNAs with platelet function. Circ Res 2016;118:420-32.

13. Willeit P, Zampetaki A, Dudek K. Circulating microRNAs as novel biomarkers for platelet activation. Circ Res 2013;112:595-600.

14. Schulte C, Molz S, Appelbaum S, et al. miRNA-197 and miRNA-223 Predict Cardiovascular Death in a Cohort of Patients with Symptomatic Coronary Artery Disease. PLoS One 2015;10:e0145930.

15. Fourdinier O, Schepers E, Metzinger-Le Meuth V. Serum levels of miR-126 and miR-223 and outcomes in chronic kidney disease patients. Sci Rep 2019;9:4477.

16. Colson PH, Gaudard P, Fellahi JL, et al. Active bleeding after cardiac surgery: a prospective observational multicenter study. PLoS One 2016;11:e0162396.

17. Dyke C, Aronson S, Dietrich W, et al. Universal definition of perioperative bleeding in adult cardiac surgery. J Thorac Cardiovasc Surg 2014;147:1458-1463.e1.

18. Malm CJ, Hansson EC, Åkesson J, et al. Preoperative platelet function predicts perioperative bleeding complications in ticagrelor-treated cardiac surgery patients: a prospective observational study. $\mathrm{Br} \mathrm{J}$ Anaesth 2016;117:309-15.

19. Bliden KP, Dichiara J, Tantry US. Increased risk in patients with high platelet aggregation receiving chronic clopidogrel therapy undergoing percutaneous coronary intervention: is the current antiplatelet therapy adequate? J Am Coll Cardiol 2007;49:657-66.

20. Chyrchel B, Totoń-Żurańska J, Kruszelnicka O. Association of plasma miR-223 and platelet reactivity in patients with coronary artery disease on dual antiplatelet therapy: A preliminary report. Platelets 2015;26:593-7.

21. Jäger B, Stojkovic S, Haller PM. Course of platelet miRNAs after cessation of P2Y12 antagonists. Eur J Clin Invest 2019;49:e13149.

22. Mayr M, Lee R, Kaudewitz D. Effects of heparin on temporal microRNA profiles. J Am Coll Cardiol 2014;63:940-1.

23. Livak KJ, Schmittgen TD. Analysis of relative gene expression data using real-time quantitative PCR and the 2- $\Delta \Delta$ CT method. Methods 2001;25:402-8.

24. Zampetaki A, Willeit P, Tilling L. Prospective study on circulating microRNAs and risk of myocardial infarction. J Am Coll Cardiol 2012;60:290-9.

25. Fejes Z, Póliska, S, Czimmerer Z. Hyperglycaemia suppresses microRNA expression in platelets to increase P2RY12 and SELP levels in type 2 diabetes mellitus.
Thromb Haemost 2017;117:529-42.

26. Landry P, Plante I, Ouellet DL. Existence of a microRNA pathway in anucleate platelets. Nat Struct Mol Biol 2009;16:961-6.

27. Keller T, Boeckel J N, Groß S. Improved risk stratification in prevention by use of a panel of selected circulating microRNAs. Sci Rep 2017;7:4511.

28. Kremke M, Tang M, Bak M. Antiplatelet therapy at the time of coronary artery bypass grafting: a multicenter cohort study. Eur J Cardiothorac Surg 2013;44:e133-e140.

29. Kwak YL, Kim JC, Choi YS. Clopidogrel responsiveness regardless of the discontinuation date predicts increased blood loss and transfusion requirement after off-pump coronary artery bypass graft surgery. J Am Coll Cardiol 2010;56:1994-2002.

30. Breet, Nicoline J. Comparison of platelet function tests in predicting clinical outcome in patients undergoing coronary stent implantation. JAMA 2010;303:754-62 .

31. Kolh P, Windecker S. ESC/EACTS myocardial revascularization guidelines 2014. Eur Heart J 2014;35:3235-6.

32. Christensen MC, Krapf S, Kempel A, et al. Costs of excessive postoperative hemorrhage in cardiac surgery. J Thorac Cardiovasc Surg 2009;138:687-93.

33. Carino A, De Rosa S, Sorrentino S, et al. Modulation of Circulating MicroRNAs Levels during the Switch from Clopidogrel to Ticagrelor. Biomed Res Int 2016;2016:3968206.

34. Harnprasopwat R, Ha D, Toyoshima T, et al. Alteration of processing induced by a single nucleotide polymorphism in pri-miR-126. Biochem Biophys Res Commun 2010;399:117-22.

35. de Boer HC, Van Solingen C, Prins J. Aspirin treatment hampers the use of plasma microRNA-126 as a biomarker for the progression of vascular disease. Eur Heart J 2013;34:3451-7.

36. Elfiky AM, Ahmed Mahmoud A, Zeidan HM. Association between circulating microRNA-126 expression level and tumour necrosis factor alpha in healthy smokers. Biomarkers 2019;24:469-77.

37. van Giezen JJ, Sidaway J, Glaves P, et al. Ticagrelor inhibits adenosine uptake in vitro and enhances adenosinemediated hyperemia responses in a canine model. J Cardiovasc Pharmacol Ther 2012;17:164-72.

38. Ganbaatar B, Fukuda D, Salim HM. Ticagrelor, a P2Y12 antagonist, attenuates vascular dysfunction and inhibits atherogenesis in apolipoprotein-E-deficient mice. Atherosclerosis 2018;275:124-32. 


\section{Page 10 of 10}

39. Wittfeldt A, Emanuelsson H, Brandrup-Wognsen G. Ticagrelor enhances adenosine-induced coronary vasodilatory responses in humans. J Am Coll Cardiol 2013;61:723-7.

40. Wallentin L, Becker RC, Budaj A. Ticagrelor versus clopidogrel in patients with acute coronary syndromes. New Engl J Med 2009;361:1045-57.

41. Cattaneo M, Schulz R, Nylander S. Adenosine-mediated effects of ticagrelor: evidence and potential clinical

Cite this article as: Wang Z, Xia L, Xu Q, Ji Q, Yao Z, Lv Q. MiR-223 levels predicting perioperative bleeding in offpump coronary artery bypass grafting. Ann Transl Med 2020;8(21):1341. doi: 10.21037/atm-20-2022b
Wang et al. MiR-223 levels predicting perioperative bleeding

relevance. J Am Coll Cardiol 2014;63:2503-9.

42. Liu X, Zhang Y, Du W. MiR-223-3p as a novel MicroRNA regulator of expression of voltage-gated $\mathrm{K}+$ channel $\mathrm{Kv} 4$. 2 in acute myocardial infarction. Cell Physiol Biochem 2016;39:102-14.

43. Meloche J, Le Guen M, Potus F, et al. miR-223 reverses experimental pulmonary arterial hypertension. Am J Physiol Cell Physiol 2015;309:C363-C372. 